\title{
Contact Point Headache- Evaluation and Surgical Treatment
}

\section{ABSTRACT}

Introduction: Contact point headache must be considered in patients who have no other identifiable cause of their headache. Otorhinolaryngologist should carefully evaluate the patients with headache for any possible contact points within the nasal cavity.

Aim: To identify the incidence of contact point headache and evaluate the results of surgery in patients suffering from contact point headache.

Materials and Methods: This longitudinal study was carried out from October 2005 to March 2006 in the Department of Otorhinolaryngology, Safdarjung Hospital, New Delhi, India. In this study 20 patients, presented to Ear, Nose and Throat Outpatient Department (ENT OPD) with complaints of headache, were screened for contact point headache. Detailed history were taken, diagnostic nasal endoscopy and computed tomography scan of nose and paranasal sinuses was done to demonstrate a contact point. A 4\% xylocaine with adrenaline (1:100000 conc.) cotton swab pack was placed between the intranasal contact point for five minutes and relief of headache was noted, if any. A total of 18 septoplasties and two Middle Turbinate (MT) lateralisations were performed. Patients were followed-up for a period of four months postoperatively.

Results: In the study, incidence of contact point headache was $13 \%$. The headache duration ranged from 18-180 months, average duration being about 45.8 months. Postoperatively, $15(75 \%)$ had total relief of their headache in terms of frequency, intensity and duration, $3(15 \%)$ patients had significant relief and $2(10 \%)$ had no relief of headache.

Conclusion: The results for surgical treatment of contact point headache in the study have been rewarding, therefore surgery should be considered in patients whose headache are refractory to all forms of medication, with intranasal contact point, as an intranasal contact point may be the trigger factor for headache.

\section{INTRODUCTION}

Headache in the absence of infection or inflammation and other causes may be related with some anatomical abnormalities of nose called contact point headache. This study adds to the body of opinion which questions the role of intranasal contact points in the aetiology of headache. Patients with headache should not only be seen by a neurologist but also by an otorhinolaryngologist, the presence of intranasal contact point documented on computed tomography scanning or nasal endoscopy is essential for the diagnosis of contact point headache. Contact point headache are headache caused by contact between the nasal septum and lateral wall by a mechanism of referred pain involving the trigeminal nerve, contact points refer to intranasal contact between opposing mucosal surfaces in the nasal cavity [1-3].

A contact point may be due to different anatomical variation like a septal spurs, deviated nasal septum and abnormalities of the turbinates [1-6]. Contact points may be a cause of secondary headaches or an exacerbating factor for primary headaches [2]. Mucosal contact headache is a newly added secondary headache disorder in the International Classification of Headache Disorder (ICHD-2). According to the ICHD-2, these headaches are characterised by intermittent pain localised in the periorbital and medial canthal or temporozygomatic regions, associated with evidence of mucosal contact points by nasal endoscopy or computed tomography imaging. The appendix of ICHD-2 defines mucosal contact point headache as a secondary disorder and requires three essential features: 1) clinical, endoscopic or imaging evidence of mucosal contact; 2) abolition of pain with local anaesthesia within five minutes after diagnostic topical application of local anaesthesia; 3) resolution of pain within seven days of surgery [7]

The pressure exerted in the contact areas due to anatomical variations, polyps or mucosal swelling can initiate the release of Substance $P$ that triggers pain impulses in afferent $C$ fibres [1-3]. Substance $P$ is a neuropeptide present in nociceptive $C$ fibres and thought to play a prominent role in pain transmission $[1-4,8,9]$. Substance $P$ has also been found in high concentrations in trigeminally derived sensory nerve endings within the nasal mucosa [9]. It exerts both an afferent and efferent function. The stimulus triggering afferent conduction is non-specific and may be inflammatory (allergic or infection), mechanical (mucosa to mucosa contact), chemical or even thermal in nature. The orthodromic impulse is not well localised by higher cortical centres (well-known phenomenon of referred pain). Therefore, the resultant pain is referred to other sites in the distribution of ophthalmic and maxillary divisions of trigeminal nerve [1-4,8]. In 1954, Williams described nasal contact headache, he felt it was due to contact between a turbinate and septum and suggested resection of the turbinate [10]. Those patients who have a history of chronic headache, in whom sinus and non-sinus disease have been ruled out, should be evaluated for contact point headache [3]. Evaluation of patients can be done with the help of nose and paranasal sinus radiographs, computed tomography scan and diagnostic nasal endoscopy. Patients suffering from headache due to endonasal contact points cannot be easily identified or clearly distinguished from patients with headache caused by other factors. It should be noted that contact point headaches and migraine without aura have similar symptoms, so it is important to differentiate contact point headaches from migraine without aura [1].

Tosun $\mathrm{F}$ et al., conducted nasal surgery for contact point headache. Improvement of contact point headache in $91 \%$ of patients was reported after surgical management. Complete relief and significant improvement of the contact point headache were observed in $43 \%$ and $47 \%$ patients respectively [3]. Kunachak S performed Middle Turbinate (MT) lateralisation- a minimally invasive method to eliminate the symptoms of contact point rhinologic cephalgia [11]. Various 
studies have shown successful results in the surgical treatment of contact point headaches $[3,11,12]$.

The present study was conducted to find the incidence of contact point headache in many patients who presented to the rhinology clinics with complain of headache, the various areas of contact giving rise to headache and the results of surgery in patients diagnosed to have contact point headache were studied.

\section{MATERIALS AND METHODS}

This longitudinal study was conducted in the Department of Otorhinolaryngology, Safdarjang hospital, New Delhi, India, from October 2005 to March 2006. The study was approved by Institutional Ethics Committee.

Inclusion criteria: History of headache with a minimum of three months duration. Presence of contact point as documented on either nasal endoscopy or computed tomography scan or both.

Exclusion criteria: Patients presenting with headache due to migraine, neuralgia, cervical spine disorders, allergy, temporomandibular joint disorders and ophthalmic problems. Patients whose headache is clearly related to sinus problems such as inflammatory disease, barotraumas or other unidentifiable pathology.

A detailed history regarding the duration, frequency and severity of headache was taken. Anterior rhinoscopy was done to look for septal deviation, spur, Inferior Turbinate (IT) hypertrophy, medialised MT and contact point between any structures in the nasal cavity. Referrals were sent to ophthalmology, neurology, dentistry to rule out any other causes of headache. Nasal cavity was then packed with cotton pledgets soaked with $4 \%$ xylocaine and adrenaline (1:100000) to decongest and note the disappearance of headache. Patients were subjected to a detailed diagnostic nasal endoscopy under local anaesthesia (4\% xylocaine with adrenaline) using a $30^{\circ}$ rigid fibreoptic endoscope, presence of any septal deviation, spur, pneumatised MT, polyp, discharge and contact point between any structure noted. X-ray paranasal sinuses (Water's view), Noncontrast computed tomography scan of nose and paranasal sinuses, axial and coronal cuts were performed in all patients.

In the present study, there were 200 patients in total that attended the ENT OPD with complaints of headache. Out of these, 26 (13\%) patients were diagnosed to have contact point headache as per ICHD-2 [7]. Out of the 26 patients, six were not willing for surgery and 20 patients gave informed consent were taken up for surgery like septoplasty, MT lateralisation and followed-up for a period of four months. Postoperatively, anterior rhinoscopy was done in all patients to assess for persistent deformity, persistent contact point, discharge and synaechia. Patients were assessed for subjective improvement in headache- total relief, significant relief and no improvement.

\section{STATISTICAL ANALYSIS}

The data were entered, processed and anlaysed in Microsoft Excel. The tables were obtained on Microsoft Word. The data was expressed as frequency and percentages using Microsoft Excel.

\section{RESULTS}

Age of the patients ranged from 18-40 years. The average age was 25 years. Seven (35\%) patients were within $11-20$ years, $9(45 \%)$ within 21-30 years and 4 (20\%) within 31-40 years of age.

The duration of headache among the study population ranged from 18-180 months. The average duration of headache was 45.8 months. Among the study population, 12 (60\%) patients had headache every day, 6 (30\%) had weekly headache and 2 (10\%) had early morning headache. Majority $\{11(55 \%)\}$ of the patients had mild intensity headache [Table/Fig-1].

Diagnostic nasal endoscopy and computed tomography showed septum in contact with MT in 11 (55\%) patients, septum in contact

\begin{tabular}{|l|c|c|c|c|c|}
\hline $\begin{array}{l}\text { Duration in } \\
\text { months }\end{array}$ & $\begin{array}{c}\text { No. of } \\
\text { patients }\end{array}$ & $\begin{array}{c}\text { Headache } \\
\text { frequency }\end{array}$ & $\begin{array}{c}\text { No. of } \\
\text { patients }\end{array}$ & $\begin{array}{c}\text { Headache } \\
\text { intensity }\end{array}$ & $\begin{array}{c}\text { No. of } \\
\text { patients }\end{array}$ \\
\cline { 1 - 2 } $0-30$ & $7(35 \%)$ & Every day & $12(60 \%)$ & Mild & $11(55 \%)$ \\
\cline { 1 - 2 } $31-60$ & $9(45 \%)$ & Weekly & $6(30 \%)$ & Moderate & $6(30 \%)$ \\
\cline { 1 - 2 } $61-90$ & 0 & Early morning & $2(10 \%)$ & Severe & $3(15 \%)$ \\
\cline { 1 - 2 } $91-120$ & $3(15 \%)$ & & & & \\
\cline { 1 - 2 } $121-150$ & 0 & & & & \\
\cline { 1 - 2 } 151-180 & $1(5 \%)$ & & & & \\
[Table/Fig-1]: Duration of headache, frequency and intensity (n=20).
\end{tabular}

with Inferior Turbinate (IT) in $3(15 \%)$ patients, spur in contact with MT in 5 (25\%) patients and spur in contact with IT in 1 (5\%) patient [Table/Fig-2].

\begin{tabular}{|l|c|c|c|c|}
\hline Contact areas & $\begin{array}{c}\text { Septum with } \\
\text { MT }\end{array}$ & $\begin{array}{c}\text { Septum with } \\
\text { IT }\end{array}$ & $\begin{array}{c}\text { Spur with } \\
\text { MT }\end{array}$ & $\begin{array}{c}\text { Spur with } \\
\text { IT }\end{array}$ \\
\hline No. of patients & $11(55 \%)$ & $3(15 \%)$ & $5(25 \%)$ & $1(5 \%)$ \\
\hline
\end{tabular}

There were 18 (90\%) septoplasties and 2 (10\%) MT lateralisation performed under local anaesthesia. Postoperatively at the end of four months, 15 (75\%) patients had total relief of their headache in terms of frequency, intensity and duration; 3 (15\%) patients had significant relief of their headache; 2 (10\%) patients had no improvement.

\section{DISCUSSION}

In the study, 200 patients with complaints of headache were screened. Out of the 200 patients, 56 patients were found to have intranasal contact point with nasal pathology, 26 (13\%) were diagnosed to have contact point headache as per the criteria ICHD-2. Out of the 26 patients, 20 patients were taken up for surgery.

Abu Bakra M and Jones NS found that the prevalence of contact point in patients with facial pain $(n=407,42 \%)$ and those without facial pain $(n=566,58 \%)$ were the same $4 \%$ [12]. There was no study which documented the incidence of contact point headache. In the study, the incidence of contact point headache was $13 \%$. Tosun $\mathrm{F}$ et al., studied 30 patients with contact points headache that underwent surgical management. The age ranged from 16 to 59 years, with mean of 32 years [3]. Gerbe RW et al., in their study on headache on nasal spur origin included patients whose age ranged from 21 to 45 years, with an average of 29.7 years [5]. Rai UL et al., found all patients with contact point headache in their study to be above 15 years and below 50 years [13]. The age range of study population in the present study was from 18 to 40 years.

The headache duration in the study ranged from 18 to 180 months [Table/Fig-1]. The average headache duration in the study was 45.8 months (3.81 years), which is less compared to 5.5 years of mean duration, reported by Mohebbi A et al., [14].

Behin $\mathrm{F}$ et al., in their study on surgical management of contact point headaches, found that 5 (45.7\%) patients had headache every day and 7 (58.3\%) had monthly headache [1]. In this study, majority $\{12(60 \%)\}$ of the patients had headache everyday, while $6(30 \%)$ had weekly headache [Table/Fig-1].

In this study, the diagnostic nasal endoscopy contact areas were similar to the computed tomography findings and all the patients had no signs of sinusitis [Table/Fig-2]. Harley DH et al., conducted a study that was designed to explore changes on clinical outcomes in a selected group of patients undergoing surgery for nasal septal and turbinate abnormalities. They pointed that the common anatomic abnormalities include septal deviations (due to deflection, buckling and spurring), turbinate deformities (concha bullosa, paradoxical curvature) and hypertrophy [15]. According to the index study, 55\% of the patients had the most frequent site of contact point between the septum and the MT [Table/Fig-2]. Tosun F et al., and Rai UL et al., also found $50 \%$ and $68 \%$ contact points between the septum and $\mathrm{MT}$, respectively $[3,13]$. 
Harley DH et al., conducted a study on 71 patients and performed 69 septoplasties, 36 unilateral turbinate reductions and 25 bilateral turbinate reductions [15]. Tosun $\mathrm{F}$ et al., performed 10 (33\%) septoplasty and turbinoplasty, 4 (13\%) septoplasty and anterior ethmoidectomy, 8 (27\%) turbinoplasty and anterior ethmoidectomy, 8 (27\%) anterior and posterior ethmoidectomy [3]. Behin $\mathrm{F}$ et al., performed surgery like septoplasty, middle turbinectomy and medial ethmoidectomy [2]. Gerbe RW et al., in his study on 20 patients, performed 2 (10\%) simple submucous resection and outfracture of their MT and 18 (90\%) septoplasties with special attention to removal of the posterior spur which is typically vomer in origin [5]. In this study, 18 (90\%) septoplasty and 2 (10\%) MT lateralisation was performed under local anaesthesia. Kunachak $S$ performed MT lateralisation in 55 patients and at the end of 2 months followup found that 48 (87\%) had complete resolution in headache [11]. Patients whose headache are refractory to all forms of medical treatment, patients with migraine without aura and cluster headache who have an intranasal contact point should be considered for surgical treatment for the removal of their contact point.

In the study, at the end of $4^{\text {th }}$ month 15 (75\%) patients had total relief of their headache, $3(15 \%)$ had significant relief and 2 (10\%) had no relief. Gerbe RW et al., sited 20 patients with recurrent unilateral headache, nasal spurs and no sinus disease who had surgery on their contact points. Nineteen patients were then followed postoperatively for 18 months-13 had complete relief, while six had partial relief [5]. Parsons DS and Batra PS reported a reduction in the intensity and frequency of headaches ( $91 \%$ and $85 \%$, respectively) in patients following endoscopic surgery to relive the contact points identified on CT scan [16]. Tosun F et al., operated 30 patients whose headache were believed to be the result of intranasal contact points. Total relief and significant improvement were achieved in 13 (43\%) and 14 (47\%) respectively, after operation [3]. Behin F et al., reported that none of the patients had any complications related to the surgery like bleeding or Cerebro Spinal Fluid (CSF) leak [1]. In this study, there were no patients with bleeding, nasal obstruction or CSF leak postoperatively, but one patient presented with synaechiae. Postoperatively, there was no relief of headache in two patients, therefore the study cannot point out the exact cause of failure of surgery after intranasal contact point removed. More careful evaluation is needed for diagnosing the patient with contact point headache.

According to the present study the surgical treatment has been successful in 15 (75\%) patients, who had total relief. The results for the surgical treatment of contact point headache have been rewarding, therefore surgery should be considered in patients whose headache are refractory to all forms of medication, with absence of sinusitis and with intranasal contact point, as an intranasal contact point may be the trigger factor for headache.

\section{Limitation(s)}

Even though surgical management of contact point headache have shown promising results, there is no explanation regarding failure of surgery which can be attributed to the small sample size.

\section{CONCLUSION(S)}

Intranasal contact point headache must be considered in patients who have no other obvious causes of headache. The use of diagnostic nasal endoscopy and sinus computed tomography scans can help to diagnose contact point headache. Surgical management should be considered in patients diagnosed to have contact point headache as results have been rewarding.

\section{REFERENCES}

[1] Behin F, Behin D, Behin D, Baredes S. Surgical management of contact point headaches. Headache the Journal of Head and Face Pain. 2005;45(3):204-10.

[2] Behin F, Behin B, Bigal ME, Lipton RB. Surgical treatment of patients with refractory migraine headaches and intranasal contact points. Cephalalgia. 2005;25(6):439-43.

[3] Tosun F, Gerek M, Ozkaptan Y. Nasal surgery for contact point headaches. Headache. 2000;40(3):237-40.

[4] Welge-Luessen A, Hauser R, Schimd N, Kappos L, Probst R. Endonasal surgery for contact point headaches: A 10-year longitudinal study. Laryngoscope. 2003;113(12):2151-56

[5] Gerbe RW, Fry TL, Fischer ND. Headache of nasal spur origin: An easily diagnosed and correctable cause of facial pain. Headache. 1984;24(6):329-30.

[6] Chow JM. Rhinologic headaches. Otolaryngol Head Neck Surg. 1994;111:211-18.

[7] Headache Classification. Committee of International Headache Society. Classification and diagnostic criteria for headache disorders, cranial neuralgias and facial pain. Cephalalgia. 1988;8(Suppl 7):01-96.

[8] Stammberger $H$, Wolf $\mathrm{G}$. Headaches and sinus disease: The endoscopic approach. Ann Otol Rhinol Laryngol. 1988;97(134):03-23.

[9] Uddman R, Malm L, Sundler F. Substance P containing nerve fibres in the nasal mucosa. Arch Otorhinolaryngol. 1983;238:09-16.

[10] Williams HL. Somatic head pain from end point of the rhinologist, otologist and laryngologist. Lancet. 1984;74:22-26.

[11] Kunachak S. Middle turbinate lateralisation: A simple treatment for rhinologic headache. Laryngoscope. 2002;112(15):870-72.

[12] Abu Bakra M, Jones NS. Prevalence of nasal mucosal contact points in patients with facial pain compared with patients without facial pain. J Laryngol Otol. 2001;115(8):629-32

[13] Rai UL, Devi PS, Singh NJ, Lyngdoh NC, Sudhiranjan T, Nongthombam N. Contact point headache: Diagnosis and management in a tertiary care center in northeast India. J Med Soc. 2018;32(1):51-56.

[14] Mohebbi A, Memari F, Mohebbi S. Endonasal endoscopic management of contact point headache and diagnostic criteria. Headache. 2010;50:242-48.

[15] Harley DH, Powitzky ES, Duncavage J. Clinical outcomes for the surgical treatment of sinonasal headache. Otolaryngol Head Neck Surg. 2003;129(3):217-21.

[16] Parsons DS, Batra PS. Functional endoscopic surgical outcomes for contact point headaches. Laryngoscope. 1998;108(5):696-702.

\section{PARTICULARS OF CONTRIBUTORS}

1. Assistant Professor, Department of Otorhinolaryngology, Zoram Medical College, Falkawn, Aizawl, Mizoram, India.

2. Senior Resident, Department of Otorhinolaryngology, Zoram Medical College, Falkawn, Aizawl, Mizoram, India

3. Senior Specialist, Department of Otorhinolaryngology, Safdarjang Hospital, New Delhi, India.

4. Professor, Department of Physiology, Zoram Medical College, Falkawn, Aizawl, Mizoram, India.

NAME, ADDRESS, E-MAIL ID OF THE CORRESPONDING AUTHOR:

Dr. P Naveen,

Professor, Department of Physiology, Zoram Medical College, Falkawn,

Aizawl-796005, Mizoram, India.

E-mail: naveenphysiol@gmail.com

\section{AUTHOR DECLARATION:}

- Financial or Other Competing Interests: None

- Was Ethics Committee Approval obtained for this study? Yes

- Was informed consent obtained from the subjects involved in the study? Yes

- For any images presented appropriate consent has been obtained from the subjects. NA
PLAGIARISM CHECKING METHODS: Jain Het al.]

- Plagiarism X-checker: Nov 03, 2020

- Manual Googling: Jan 25, 2021

- iThenticate Software: Feb 17, 2021 (16\%)
ETYMOLOGY: Author Origin

Date of Submission: Oct 30, 2020 Date of Peer Review: Dec 21, 2020 Date of Acceptance: Feb 03, 2021 Date of Publishing: Apr 01, 2021 